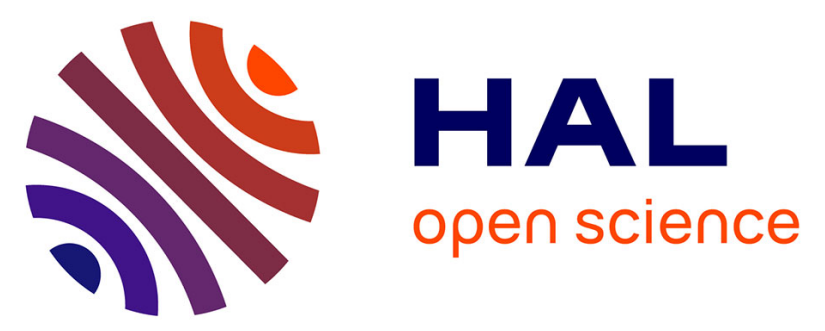

\title{
Straightforward Access to Stable, 16-Valence-Electron Phosphine-Stabilized Fe Olefin Complexes and Their Reactivity
}

Benjamin Burcher, Kevin J Sanders, Ladislav Benda, Guido Pintacuda, Erwann Jeanneau, Andreas A. Danopoulos, Pierre Braunstein, Hélène Olivier-Bourbigou, Pierre-Alain Breuil

\section{To cite this version:}

Benjamin Burcher, Kevin J Sanders, Ladislav Benda, Guido Pintacuda, Erwann Jeanneau, et al.. Straightforward Access to Stable, 16-Valence-Electron Phosphine-Stabilized Fe Olefin Complexes and Their Reactivity. Organometallics, 2017, 36 (3), pp.605-613. 10.1021/acs.organomet.6b00803 . hal01503473

\section{HAL Id: hal-01503473 \\ https://hal.science/hal-01503473}

Submitted on 2 May 2018

HAL is a multi-disciplinary open access archive for the deposit and dissemination of scientific research documents, whether they are published or not. The documents may come from teaching and research institutions in France or abroad, or from public or private research centers.
L'archive ouverte pluridisciplinaire HAL, est destinée au dépôt et à la diffusion de documents scientifiques de niveau recherche, publiés ou non, émanant des établissements d'enseignement et de recherche français ou étrangers, des laboratoires publics ou privés. 


\title{
A Straightforward Access to Stable, 16 Valence-electron Phosphine- Stabilized $\mathrm{Fe}^{0}$ Olefin Complexes and their Reactivity
}

\author{
Benjamin Burcher, ${ }^{a}$ Kevin J. Sanders, ${ }^{b}$ Ladislav Benda, ${ }^{b}$ Guido Pintacuda, ${ }^{b}$ Erwann Jeanneau, ${ }^{c}$ Andreas A. \\ Danopoulos, ${ }^{\mathrm{d}}$ Pierre Braunstein, ${ }^{\mathrm{d}}$ Hélène Olivier-Bourbigou ${ }^{\mathrm{a}}$ and Pierre-Alain R. Breuil ${ }^{\text {*a }}$ \\ a IFP Energies nouvelles, Rond-point de l'échangeur de Solaize, BP 3, 69360 Solaize, France \\ ${ }^{\mathrm{b}}$ Université de Lyon, Institut des Sciences Analytiques (UMR 5280 CNRS / Université Claude Bernard Lyon 1 / ENS de \\ Lyon), 5 rue de la Doua, 69100 Villeurbanne, France \\ c Centre de Diffractométrie Henri Longchambon, Site CLEA - Bât. ISA, 3ème étage, 5 rue de La Doua, 69100 Villeurbanne, \\ France \\ ${ }^{d}$ Université de Strasbourg, CNRS, CHIMIE UMR 7177, Laboratoire de Chimie de Coordination, 4 rue Blaise Pascal, \\ CS90032, 67081 Strasbourg, France
}

Supporting Information Placeholder

\begin{abstract}
The use of the dialkene divinyltetramethyldisiloxane (dvtms) allows easy access to the reactive 16 valence-electron complexes $\left[\mathrm{Fe}^{0}(\mathrm{~L}-\mathrm{L})(\mathrm{dvtms})\right],(\mathrm{L}-\mathrm{L})=$ dppe (1,2-bis(diphenylphosphino)ethane), (1), dppp (1,2-bis(diphenylphosphino)propane), (2), pyN$\mathrm{MeP}\left(\mathrm{Pr}_{2} \quad\right.$ (N-(diisopropylphosphino)-N-methylpyridin-2-amine), (4), dipe (1,2-bis(diisopropylphosphino)ethane), (5), and $\left[\mathrm{Fe}^{0}(\mathrm{~L})_{2}(\mathrm{dvtms})\right], \mathrm{L}=\mathrm{PMe}_{3},(3)$, by a mild reductive route using $\mathrm{AlEt}_{2}(\mathrm{OEt})$ as reducing agent. In contrast, by the same methodology, the 18 valence-electron complexes $\left[\mathrm{Fe}^{\mathrm{O}}(\mathrm{L}-\mathrm{L})_{2}(\mathrm{ethylene})\right],(\mathrm{L}-\mathrm{L})=\mathrm{dppm}(1,2-\mathrm{bis}$ (diphenylphosphino)methane), 6, (L-L) = dppa (1,2bis(diphenylphosphino)amine) 7 or $(\mathrm{L}-\mathrm{L})=\mathrm{dppe}, 8$, were obtained, which do not contain dvtms. In addition, a combined DFT and solid-state paramagnetic NMR methodology is introduced for the structure determination of 5 . A comparative study of the reactivity of 1,2,4-6 and 8 with 3-hexyne highlights emerging mechanistic implications for C-C coupling reactions using these complexes as catalysts.
\end{abstract}

\section{INTRODUCTION}

The catalytic chemistry of iron complexes is being intensively revisited with the objective to develop surrogates for noble metals in homogeneous catalysis. ${ }^{1}$ Recent progress has led to Fe complexes in various oxidation states with unprecedented reactivities. ${ }^{2}$ In particular, over the last decade, low-valent iron chemistry has enjoyed a renaissance thanks to well-defined complexes, which are catalytically competent in numerous transformations. ${ }^{3}$ Indeed, the synthesis of well-defined low-valent Fe complexes is crucial for a better understanding of the mechanisms operating in Fe-catalyzed reactions. Among low-valent $\mathrm{Fe}$ complexes, nitrogen-donor ligand-based $\mathrm{Fe}$ complexes currently constitute the mainstream of the ongoing research efforts, ${ }^{4,5}$ although the possible non-innocent character of certain N-ligands often casts doubt on the metal oxidation state in these coordination compounds. ${ }^{6}$ An alternative approach employs phosphorus donor ligands, since their easily-tunable electronic and steric properties are advantageous to stabilize low oxidation state metal complexes. Indeed, numerous examples have been described, where low-oxidation state iron complexes are stabilized by phosphorus based ligands. ${ }^{7}$ However, they almost invariably feature 18 valence-electron (ve) metal centers, with limited reactivity due to their coordinatively and electronically saturated nature. For this reason we focused our effort on accessing well-defined, coordinatively unsaturated, thus more reactive, P-based species, typically 16 ve $\mathrm{Fe}^{0}$ complexes. Isolated and well-characterized examples of the latter are scarce, ${ }^{8,9,10,11}$ a fortiori low-coordinate 16 ve $\mathrm{Fe}^{0}$ centers with alkene and mono- or bidentate P-donor ligands. The only reported examples of the latter with alkyl phosphines have to be handled at temperatures below $0^{\circ} \mathrm{C}$ to avoid decomposition, which limits the study of their reactivity. ${ }^{9}$ Very recently, $\left[\mathrm{Fe}^{\mathrm{O}}(\operatorname{dipp})\left(\mathrm{C}_{2} \mathrm{H}_{4}\right)_{2}\right]$, dipp = bis(diisopropylphosphino) propane was described by Fürstner et al. ${ }^{10}$ Remarkably, while most reported 16 ve $\mathrm{Fe}^{0}$ complexes bearing P-donor ligands were accessed via conventional reducing routes based on the use of sodium, potassium or magnesium, $\left[\mathrm{Fe}^{0}(\operatorname{dipp})\left(\mathrm{C}_{2} \mathrm{H}_{4}\right)_{2}\right]$, as well as the complexes described in the present work were obtained by the uncommon "reductive alkylation" methodology. Furthermore, it has to be emphasized that Deng and coworkers introduced the use of chelating functionalized organosilicons associated to bulky monodentate aminocarbenes to ensure the synthesis and isolation at ambient temperature of well-defined 14- and 16 ve $\mathrm{Fe}^{0}$ species. ${ }^{11}$ Prior this work, the use of such organosilicon derivatives were scarcely reported on ironcarbonyl complexes ${ }^{12}$ and other transition metals such as nickel or palladium. ${ }^{13}$

Herein, we report the straightforward synthesis and characterization of various stable 16 valence-electron $\mathrm{Fe}^{0}$ alkene complexes bearing mono- and/or bidentate donor ligands and illustrate their potential in terms of reactivity in the oxidative coupling of alkynes. ${ }^{10,14,15}$ Moreover, while the 3D structure of complex 5 could 
not be determined by X-ray crystallography, we obtained the coordinates de novo by density functional theory (DFT) calculations and utilized solid-state paramagnetic NMR (PNMR) spectroscopy to validate the resulting model.

\section{RESULTS AND DISCUSSION}

Synthesis and Characterization of the 16 ve Complexes 1-5. In the search for a mild reductive methodology to access reactive 16 ve complexes comprising $\left[\mathrm{Fe}^{\mathrm{O}}(\mathrm{L}-\mathrm{L})\right]$ and $\left[\mathrm{Fe}^{\mathrm{O}}(\mathrm{L})_{2}\right]$ fragments, $\mathrm{L}$ being a 2-electron $\mathrm{P}$ - or $\mathrm{N}$-donor, we carefully investigated the reductive/alkylating reactivity of the commercial $\mathrm{AlEt}_{2}(\mathrm{OEt})$, previously employed for the synthesis of the 18 ve $\left[\mathrm{Fe}(\mathrm{dppe})_{2}\left(\mathrm{C}_{2} \mathrm{H}_{4}\right)\right]$, dppe $=$ $\mathrm{Ph}_{2} \mathrm{P}\left(\mathrm{CH}_{2}\right)_{2} \mathrm{PPh}_{2}{ }^{16}$ Addition of one equivalent of dppe at room temperature to a mixture of divinyltetramethyldisiloxane (dvtms), $\left[\mathrm{Fe}(\mathrm{acac})_{3}\right]$ and $\mathrm{AlEt}_{2}(\mathrm{OEt})$ in an optimized ratio (see below), afforded the new 16 ve dialkene complex $\left[\mathrm{Fe}^{0}(\mathrm{dppe})(\mathrm{dvtms})\right](1)$ as a green solid ( $81 \%$ yield). This method was then applied similarly, except substituting dppe with $\mathrm{Ph}_{2} \mathrm{P}\left(\mathrm{CH}_{2}\right)_{3} \mathrm{PPh}_{2}$ (dppp) affording the analogous green complex [ $\left.\mathrm{Fe}^{0}(\mathrm{dppp})(\mathrm{dvtms})\right]$ (2) in $71 \%$ yield (Scheme 1). Encouraged by the versatility of this straightforward approach, we employed $\mathrm{PMe}_{3}$ in place of (L-L) and isolated at low temperature $\left(-80{ }^{\circ} \mathrm{C}\right)$ the highly air-sensitive blue solid $\left[\mathrm{Fe}^{\mathrm{O}}\left(\mathrm{PMe}_{3}\right)_{2}(\mathrm{dvtms})\right](3)$, but in low yield $(19 \%)$, arguably because of its high solubility in all common solvents, including pentane. Furthermore, mixed bidentate $\mathrm{P}, \mathrm{N}$ ligands also appeared to be suitable for this methodology, since under similar conditions the use of pyNMePi $\mathrm{Pr}_{2}$ led to the brown complex $\left[\mathrm{Fe}^{\mathrm{O}}\left(\mathrm{pyNMeP}^{\mathrm{i}} \mathrm{Pr}_{2}\right)(\mathrm{dvtms})\right]$ (4) in $48 \%$ yield (Scheme 1$)$. With stronger $\sigma$-donor bidentate phosphines, such as ${ }^{i} \mathrm{Pr}_{2} \mathrm{P}\left(\mathrm{CH}_{2}\right)_{2} \mathrm{P}^{i} \mathrm{Pr}_{2}$ (dipe), the corresponding $\left[\mathrm{Fe}^{0}\right.$ (dipe)(dvtms)] (5) was readily isolated as a blue solid (up to $81 \%$ yield) (Scheme 1 ).

Scheme 1. Synthesis of complexes 1-5.
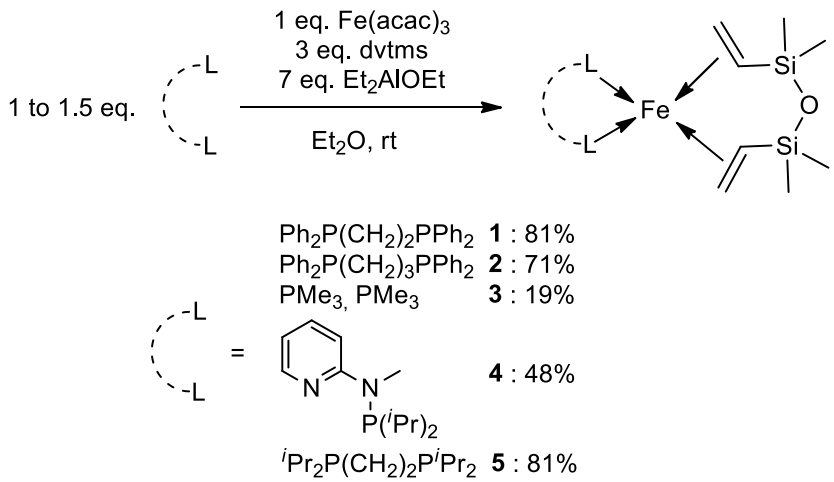

Single-crystal X-ray diffraction studies established the structures of the $\left[\mathrm{Fe}^{0}(\mathrm{~L}-\mathrm{L})(\mathrm{dvtms})\right]$ and $\left[\mathrm{Fe}^{0}(\mathrm{~L})_{2}(\mathrm{dvtms})\right]$ complexes 1-4 and revealed the $\eta^{2}: \eta^{2}$ coordination mode of the dvtms (Figure 1). The metal coordination geometry in 1 can be considered as distorted tetrahedral; the C-C bond distances in the vinyl moiety of 1.409(5) $\AA$ and 1.419(5) $\AA$ are indicative of $d \rightarrow \pi^{*}$ back donation. ${ }^{11}$ Similarly, the structures of 2 and 3 exhibit distorted tetrahedral coordination geometries; the molecule of 3 exhibits $\mathrm{C}_{2 v}$ symmetry (relative to the $\mathrm{Fe}-\mathrm{O}$ axis). Significant structural differences are observed in 4 , where the two vinyl moieties are coplanar (torsion angle of $4.22^{\circ}$ ) and perpendicular to the plane of the ligand containing the $\mathrm{P}, \mathrm{N}$ and $\mathrm{N}_{\mathrm{py}}$ atoms. The $\mathrm{P}$ and $\mathrm{Fe}$ atoms lie almost in the plane formed by the vinyl fragments so that the coordination geometry of 4 is best described as trigonal pyramidal.
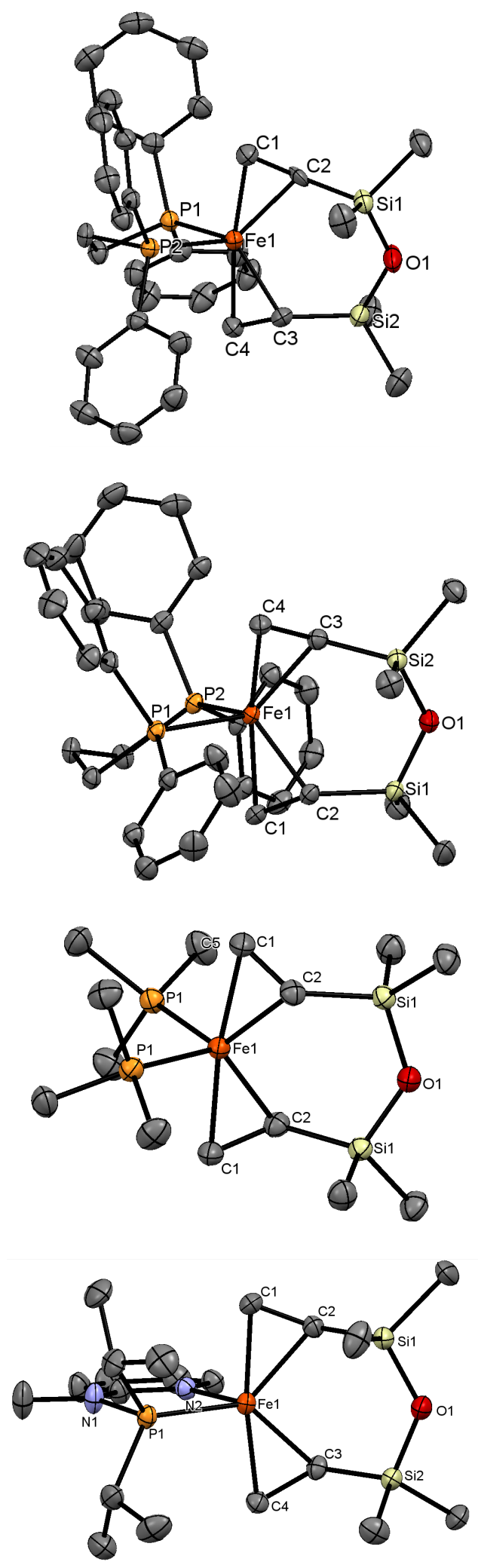

Figure 1. Thermal ellipsoid representation (at $50 \%$ probability) of complexes (from top to bottom) 1, 2, 3 and 4; $\mathrm{H}$ atoms are not shown for clarity. Selected bond lengths $(\AA)$ and angles $\left(^{\circ}\right)$ : For 1: P1-Fe1-P2 84.75(3); P1-Fe1 2.302(10); P2. Fe1 2.316(10); C3-C4 1.419(5); C1-C2 1.409(5); for 2: P1-Fe1-P2 91.37(2); P1Fe1 2.291(6); P2-Fe1 2.335(6); C3-C4 1.418(3); C1-C2 1.415(3); for 3: P1-Fe1-P1 
NMR-Validated de novo DFT Structure of 5. Because no single crystals suitable for X-ray diffraction could be obtained for $\mathbf{5}$, we constructed a putative structural model by de novo DFT optimization (Figure 2, (b), see Experimental) and confirmed the dipe ligand binding to $\mathrm{Fe}^{0}$ by using PNMR calculations ${ }^{17}$ and PNMR spectroscopy of a precipitated powder sample which was also characterized by elemental analysis. Previous reports described that DFT may provide high-quality structures of high-spin open-shell transition metal complexes, in excellent agreement with those obtained by experimental structural determination with $\mathrm{X}$-ray diffraction. ${ }^{18}$ Reliable DFT methodology requires a proper functional, a sufficiently large atomic basis, and a dispersion correction properly accounting for van der Walls forces. The method chosen here (see Computational Details) meets all these demands. The energy minimum found by the DFT structure optimization for complex 5 indeed very closely resembles the X-ray structure of related complex 1, as shown in Figure 2.

To support the DFT-optimized structure, we measured and calculated ${ }^{13} \mathrm{C}$ PNMR shifts of 5 . NMR spectra of paramagnetic complexes contain a wealth of structural information since the unpaired electrons induce large perturbations in the chemical shifts and the NMR relaxation properties of the surrounding nuclei. These PNMR effects depend on the distribution of unpaired electron density ("spin density") on the ligands, which in turn is highly sensitive to the metal binding and the conformation of the ligands. ${ }^{19}$

The spin density provides a qualitative insight into this phenomenon (Figure 2, (c)). Notably, negative unpaired electron density and large negative contact shifts are predicted for the ${ }^{13} \mathrm{C}$ nuclei of the $-\left(\mathrm{CH}_{2}\right)_{2}$ - bridge. The corresponding experimental ${ }^{13} \mathrm{C}$ NMR spectrum was acquired under magic-angle spinning conditions on a powdered sample of 5 (Figure 2, (d)). The magnitude of the experimental ${ }^{13} \mathrm{C}$ shifts is often overestimated in the DFT calculations (see below), but a few assignments can be reliably established in the less crowded regions of the spectrum. This is the case around -1000 ppm, where only two very broad ${ }^{13} \mathrm{C}$ signals are observed, and directly assigned to the $-\left(\mathrm{CH}_{2}\right)_{2}$ - bridge of the dipe ligand coordinated to $\mathrm{Fe}^{0}$. We note in passing that without extensive further modeling such a clear assignment could not be made for any other resonances in the PNMR spectra of 5 (see Discussion of the computational protocol below). Nevertheless, the agreement between the experimental and predicted shifts for the $-\left(\mathrm{CH}_{2}\right)_{2}$ - bridge confirms the dipe binding to $\mathrm{Fe}^{0}$ and, by extension, the putative structure of complex 5 . (a)

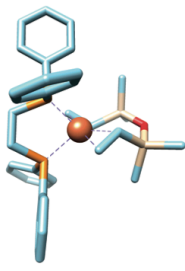

(b)

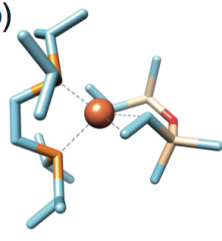

(c)

(d)

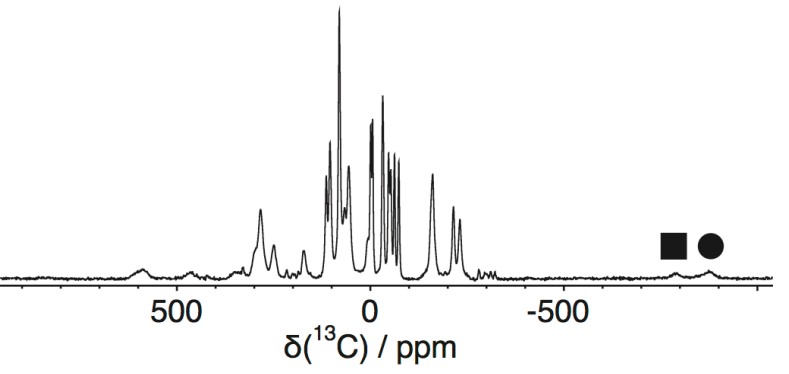

Figure 2. (a) X-ray structure of 1 ( $\mathrm{H}$ atoms not shown for clarity). (b) DFToptimized structure of 5. (c) Visualization of positive (blue) and negative (red) isosurfaces of spin density distribution in $\mathbf{5}$ (for \pm 0.0002 a.u. isovalues). (d) ${ }^{13} \mathrm{C}$ PNMR spectrum of 5. The two $\mathrm{CH}_{2}$ carbons and their signals are labeled with a circle and a square in panels $(\mathrm{c}-\mathrm{d})$.

Discussion of the PNMR Computational Protocol. The main accuracy limiting factors of our modeling approach were: (1) the method for calculating the spin-orbit coupling (SOC)-dependent electron paramagnetic resonance (EPR) property tensors $g$ and $D$, (2) the method for hyperfine coupling (HFC) calculations, and (3) the quality and relevance of the molecular structure for which the PNMR calculations were performed to the experimental conditions in the molecular crystal.

(1) Reliable $\mathrm{g}$ - and D-tensor calculations in $3 \mathrm{~d}$ transition metal complexes require the use of correlated multi-reference $a b$ initio methods. Performing such calculations for systems as large as $\sim 80$ atoms is currently at the very limit of standard computational capabilities. Comparing PNMR shifts calculated without and with DFT-based SOC property tensors $g$ and $D$ (Table 1), we see that upon inclusion of the SOC-dependent property tensors the PNMR shifts decrease by several tens of ppm. Comparable or perhaps even slightly larger effects might be expected when using $a b$ initio $g$-and D-tensors.

(2) To the best of our knowledge, there is currently no benchmark $a b$ initio method for reliable HFC calculations. Pure (generalized gradient approximation Kohn-Sham) DFT is known to over-delocalize spin density from the metal center ${ }^{20}$ leading to overestimation of the Fermi-contact HFCs and shifts on the metal ligand atoms, which in this case dominate the total HFC and PNMR shifts. Adding exact exchange admixture in hybrid DFT usually improves the results ${ }^{21}$ but this improvement can be nonsystematic and non-uniform across the NMR-active atoms of the molecule. Only qualitative accuracy of the calculated Fermi-contact HFCs and shifts may be expected from our PBEO HFC calculations.

(3) Even though there is an overall agreement between DFToptimized structure of $\mathbf{5}$ and the X-ray structure of the closely related complex 1 , only a qualitative agreement between the PNMR calculations and the experiment can be expected in view of the high sensitivity of the PNMR shifts to the metal coordination geometry. The influence of a strong structural dependence of the PNMR shifts becomes important when internal dynamics at the metal center takes place. Modeling the dynamical effects on PNMR shifts, albeit potentially worthwhile and relevant for molecular crystals with flexible groups, goes beyond the scope of this article. 
Table 1. Experimental and calculated ${ }^{13} \mathrm{C}$ NMR shifts (in ppm, relative to TMS) of the - $\left(\mathrm{CH}_{2}\right)_{2}$ - bridge of the bidendate dipe ligand.

\begin{tabular}{|c|c|c|c|}
\hline Structure & $g, D$ & $P N M R^{b}$ & $\delta_{\mathrm{C}}$ \\
\hline $\mathrm{DFT}^{a}$ & - & no SOC & $-1017,-1052$ \\
\hline DFT $^{a}$ & DFT & full & $-1047,-1085$ \\
\hline Exp. & & & $-800,-890$ \\
\hline
\end{tabular}

Synthesis and Characterization of the 18 ve Complexes 6-8. Strikingly, we observed considerable differences when the synthetic methodology used to access 1-5 was applied to the small bite angle bidentate ligands bis(diphenylphosphino)methane (dppm) or bis(diphenylphosphino)amine) (dppa). In these cases, the added dvtms did not enter the coordination sphere, which now comprises two bidentate phosphines and one ethylene ligand in the 18 ve complexes $\left[\mathrm{Fe}^{\mathrm{O}}(\mathrm{dppm})_{2}\left(\mathrm{C}_{2} \mathrm{H}_{4}\right)\right](6)$ and $\left[\mathrm{Fe}^{\mathrm{O}}(\mathrm{dppa})_{2}\left(\mathrm{C}_{2} \mathrm{H}_{4}\right)\right]$ (7), respectively. The origin of the ethylene ligand is presumably due to $\beta$ $\mathrm{H}$ elimination from a $\mathrm{FeEt}_{2}$ moiety formed in situ, from which also ethane (detected by GC) can arise, via reductive elimination from the transient $\mathrm{Fe}(\mathrm{H}) \mathrm{Et}$ moiety. ${ }^{22}$ Optimized yield of the orange complex $6(83 \%)$ was obtained by adjusting the mole ratio diphosphine/Fe to 2, without addition of dvtms (Scheme 2). The use of dppa led to complex 7 in a priori high yield (87\%), however important inconsistencies were observed in elemental analyses (see Experimental). Suitable single crystals of X-ray diffraction quality could however be grown for structure determination. The previously characterized (by elemental analysis and IR spectroscopy) red complex $\left[\mathrm{Fe}^{\mathrm{O}}(\mathrm{dppe})_{2}\left(\mathrm{C}_{2} \mathrm{H}_{4}\right)\right](8)$ was also obtained by this method in $85 \%$ yield. ${ }^{16}$ The diamagnetic complexes 6 and 8 were characterized by elemental analyses and ${ }^{1} \mathrm{H}$ and ${ }^{31} \mathrm{P}$ NMR spectroscopic methods. The ${ }^{31} \mathrm{P}$ NMR spectrum of $8\left(20^{\circ} \mathrm{C}\right.$ in $\left.\mathrm{C}_{6} \mathrm{D}_{6}\right)$ contains a pair of triplets at $\delta 78.8$ and $95.5 \mathrm{ppm}$, assignable to the two groups of non-equivalent $\mathrm{P}$-atoms of the dppe ligands $\left(\mathrm{A}_{2} \mathrm{X}_{2}\right.$ spin system). In contrast, in the ${ }^{31} \mathrm{P}$ NMR spectrum of $6,\left(20^{\circ} \mathrm{C}, \mathrm{C}_{6} \mathrm{D}_{6}\right)$ the four equivalent phosphorus nuclei of the dppm ligands appear as a broad singlet at $\delta 23.9 \mathrm{ppm}$, as reported previously. ${ }^{23}$ In the ${ }^{1} \mathrm{H}$ NMR spectrum of 8 , the coordinated ethylene gives rise to two broad signals at $\delta 0.93$ and $1.13 \mathrm{ppm}$, the latter overlapping with two protons of the ligand backbone.

Scheme 2. Synthetic route to complexes 6-8.

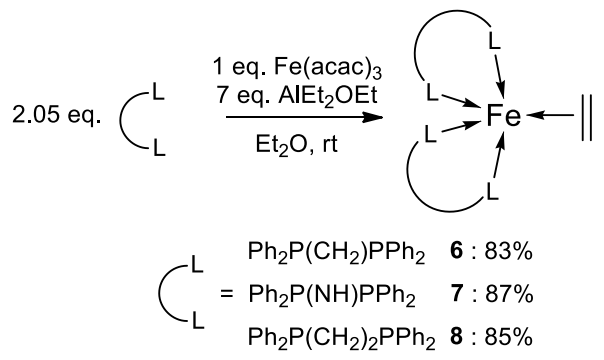

The structures of 7 and 8, determined crystallographically, exhibit trigonal bipyramidal coordination geometries (calculated values of T: 0.96 for 7 and almost 1 for 8 , Figure 3 and Figure 4). The Fe$\mathrm{C}_{\text {ethylene }}(2.082(8)$ and $2.099(7) \AA)$ bond distances in 8 are larger than those in complex 7 (2.069(2) and 2.050(2) $\AA$ ), consistent with a greater back donation from the Fe(dppe $)_{2}$ moiety to the ethylene, compared to Fe(dppa) $)_{2}$. Noteworthy, the PNHP atom in 7, localized in the difference Fourier map of the crystal structure determination, did not react with the excess of $\mathrm{AlEt}_{2}(\mathrm{OEt})$ used in the synthesis, opening future possibilities of ligand proton responsiveness during catalysis.

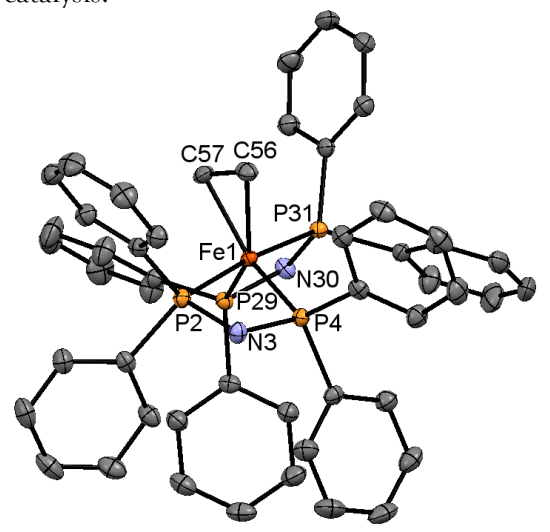

Figure 3.Thermal ellipsoid representation (at $50 \%$ probability) of complex 7 . H atoms are not shown for clarity. Selected bond length $(\AA)$ and angles $\left({ }^{\circ}\right)$ : P2-Fe1P4 71.70(2); P29-Fe1-P31 71.78(2); C57-C56 1.423(3); C56-Fe1 2.069(2); C57Fe1 2.050(2); P4-Fe1 2.189(6); P2-Fe1 2.209(6); P31-Fe1 2.198(6); P29-Fe1 2.175(6)

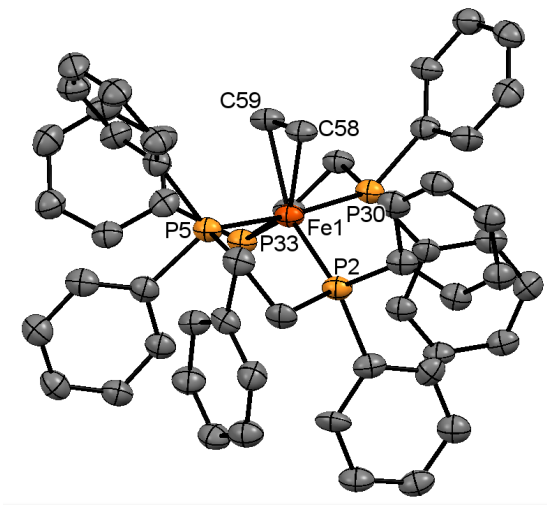

Figure 4. Thermal ellipsoid representation (at $50 \%$ probability) of complex 8 ( $50 \%$ probability displacement ellipsoids). $\mathrm{H}$ atoms are not shown for clarity. Selected bond length $(\AA)$ and angles $\left({ }^{\circ}\right)$ : P2-Fe1-P5 84.35(8); P33-Fe-P30 83.72(8); C59-C58 1.441(11); C59-Fe1 2.082(8); C58-Fe1 2.099(7); P5-Fe1 2.229(2); P2Fe1 2.238(2); P33-Fe1 2.214(2); P30-Fe1 2.210(2). 
Cyclotrimerization of Alkynes. We then considered the cyclotrimerization of 3-hexyne as a model reaction to compare the reactivity of the 16 and 18 ve complexes (see Table 2). Up to $35 \%$ conversion was obtained with 1 leading to exclusive formation of hexaethylbenzene (HEB). Increasing the bite angle of the ligand from dppe to dppp (as in 1 and 2, respectively) disfavors 3-hexyne conversion (12\%); in addition, the mixed donor ligand in 4 does not lead to an efficient catalyst (11\% conversion to HEB). The conversion of 3-hexyne was higher with 5 than with 1 (49\% vs. $35 \%$, respectively), however, cyclic and linear C12 products accompanied HEB formation. Postulating the involvement of a metallacyclic reaction mechanism, the lower selectivity with $\mathbf{5}$ could be rationalized by the steric hindrance brought about by the isopropyl P-substituents that hampers coordination of a third molecule of 3-hexyne to the 16 ve intermediate $\mathrm{C}$ and thus the formation of the metallacycle D precursor to HEB (see Scheme 3). The catalytic results with the 18 ve complexes 6 and 8 clearly highlight the reduced accessibility of the metal by the 3-hexyne substrate: 6 and 8 gave no conversion; catalytic results obtained with 7 were not explored because of concerns about the purity of the sample. Mechanistically, it is reasonable to assume that the reaction initiation involves displacement of the coordinated ethylene by an alkyne. However, propagation by metallacycle formation requires coordination of one additional alkyne, which is prevented by a disfavored dissociation of at least one P-donor.

Table 2. Catalyzed cyclo-trimerization of 3-hexyne.

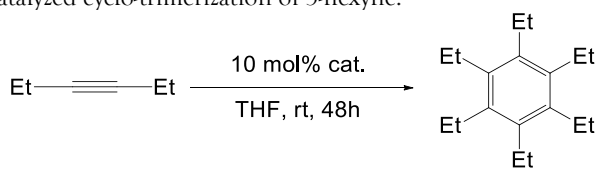

\begin{tabular}{cc}
\hline Catalyst & Conversion (Selectivity HEB) (wt \%) ${ }^{\mathrm{a}}$ \\
\hline 1 & $35(100)$ \\
2 & $12(100)$ \\
4 & $11(100)$ \\
5 & $49(48.2)$ \\
6 & $0(-)$ \\
8 & $0(-)$
\end{tabular}

Conditions: catalyst $(0.20 \mathrm{mmol})$, 3-hexyne $(2.0 \mathrm{mmol})$, r.t., THF $(5 \mathrm{~mL}), 48$ h. ${ }^{\text {a }}$ determined by GC-MS.

Scheme 3. Suggested mechanism for alkyne cyclo-trimerization.

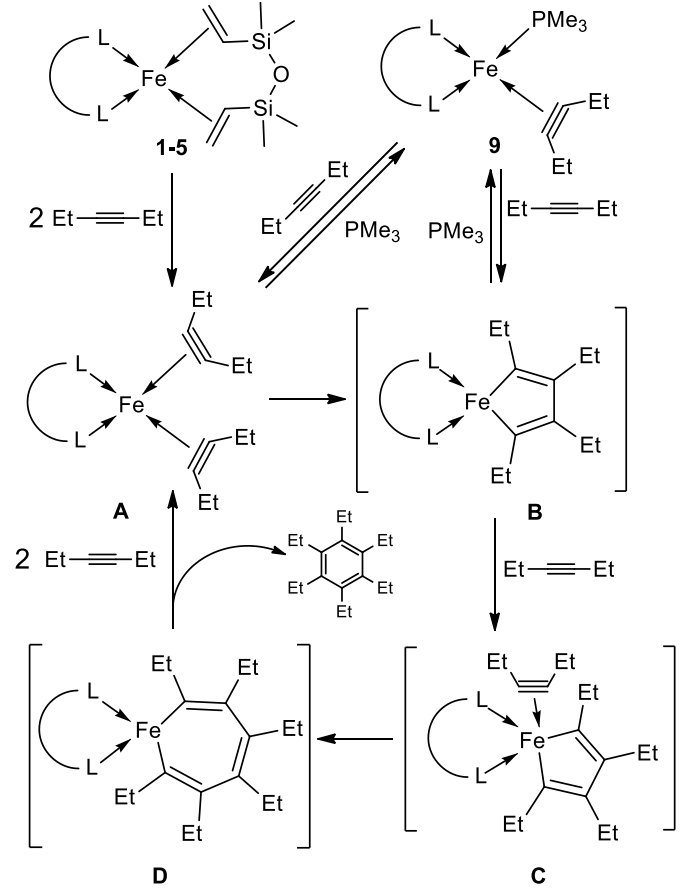

Synthesis and Characterization of 9. With the aim to observe or trap suggested reaction intermediates such as the bis(alkyne) iron species A or the iron-cyclopentadiene-like moiety B ensuing from the oxidative coupling of two alkynes (Scheme 3), we exposed 1 to 3-hexyne. This resulted in an immediate color change from green to brown; however, no complex could be isolated. Addition of few equivalents of $\mathrm{PMe}_{3}$, in order to trap the reactive species as a stable 18 ve species, unexpectedly led to the clean isolation in moderate yields (28\%) of the air-sensitive, green diamagnetic complex [Fe(dppe)( $\left.\mathrm{PMe}_{3}\right)$ (3-hexyne)] (9), which was characterized by ${ }^{1} \mathrm{H},{ }^{31} \mathrm{P}$ and ${ }^{13} \mathrm{C}$ NMR spectroscopy and crystallographically (Figure 5). The XRD study confirmed that this unprecedented complex features one alkyne, one bidentate dppe and one $\mathrm{PMe}_{3}$ ligands. The coordination geometry at Fe can be described as tetrahedral or distorted square pyramidal, depending on whether the unsaturated ligand is considered as an $\eta^{2}$-alkyne or a $\kappa \mathrm{C}, \kappa \mathrm{C}$-metallacyclopropene. The much elongated C-C bond distance in the hexyne ligand (1.303(6) $\AA$ ) compared to that in free 3-hexyne (1.210 $\AA$ ), falls in the range associated with $\mathrm{C}=\mathrm{C}$ double bonds and implies substantial back donation from the metal to the $\pi^{*}$-orbital(s) of the alkyne, thus supporting the description of the coordinated 3-hexyne as metallacyclopropene. ${ }^{13} \mathrm{C}$ NMR spectrum analysis supports this hypothesis as a downfield-shifted chemical shift at 189 ppm is measured, corresponding 4-electron donor acetylene ligand (see Experimental). Although a plausible precursor to 9 could be the bis(3hexyne) species A, it may also be considered as arising by cleavage of the postulated iron-cyclopentadiene $\mathbf{B}$ after the addition of $\mathrm{PMe}_{3}$ (Scheme 3). In this case A and B should be in equilibrium. 


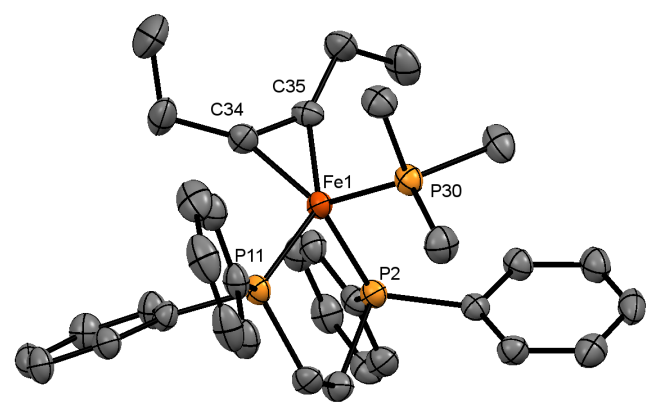

Figure 5. Thermal ellipsoid representation (at 50\% probability) of complex 9 . H atoms are not shown for clarity. Selected bond length $(\AA)$ and angles $\left(^{\circ}\right)$ : P11-Fe1P2 86.76(5); P11-Fe1 2.1501(14); P2-Fe1 2.136(14); P30-Fe1 2.150(14); Fe1-C34 1.874(5); Fe1-C35 1.860(5); C34-C35 1.303(6).

\section{CONCLUSIONS}

In conclusion, we described a convenient reductive path to 16 valence-electron $\mathrm{Fe}^{0}$ reactive species. The successful synthesis of a range of olefin complexes bearing monodentate and bidentate phosphines or $\mathrm{P}, \mathrm{N}$ hybrid ligands demonstrates its versatility and scope. The nature of the P-donor ligand determines the coordination of the final product, as demonstrated by the selective isolation of the 18 ve complexes with small bite angle diphosphines. The dvtms-stabilized 16 ve species showed a better propensity to yield hexaethylbenzene as a cyclo-trimerization product of 3-hexyne, than their 18 ve counterparts. This direct access to valuable $\left[\mathrm{Fe}^{\mathrm{O}}(\mathrm{L})_{2}\right]$ fragments opens perspectives for mechanistic investigations of reactions involving oxidative addition and coupling as elementary steps. Finally, because X-ray crystallography could not be used to determine the structure of $\mathbf{5}$, we established a putative structural model de novo using DFT optimization and used paramagnetic solid-state NMR spectroscopy to validate this model.

\section{EXPERIMENTAL}

General Considerations Unless stated otherwise, all reactions were carried out under atmosphere of argon using standard Schlenk techniques. All reagents were purchased from commercial suppliers and used without further purification. All yields refer to isolated products. Anhydrous common solvents were purified by solvent purification system (SPS-M-Braun). NMR spectra were recorded on a Bruker AV $300 \mathrm{MHz}$. Deuterated solvents were purchased from Sigma-Aldrich or Eurisotop. GC-MS analyses were carried out with an Agilent $6890 \mathrm{~N}$ apparatus equipped with a PONA or HP-MS column and an Agilent 5975B inert XL EI/CI MSD mass spectrometer. FT-IR spectra were recorded in the solid state by ATR Golden Gate (Specac) on a Perkin-Elmer spectrum one spectrometer. Elemental analyses were determined at London Metropolitan University. Abbreviations used in the experimental section are as follows: dvtms = divinyltetramethyldisiloxane, dipe $=$ 1,2-bis(diisopropylphosphino)ethane, dppe $=1,2$ bis(diphenylphosphino)ethane, $\quad \mathrm{dppp} \quad=\quad 1,2$ bis(diphenylphosphino)propane, $\quad$ pyNMeP $\left({ }^{i} \operatorname{Pr}\right)_{2}=\mathrm{N}$ (diisopropylphosphino)-N-methylpyridin-2-amine, $\mathrm{dppm}=1,2$ bis(diphenylphosphino)methane, $\quad \mathrm{dppa} \quad=\quad 1,2$ bis(diphenylphosphino)amine.

[Fe(dppe)(dvtms)] (1). 1,2-Bis(diphenylphosphino)ethane $(0.60 \mathrm{~g}$, $1.51 \mathrm{mmol}, 1.03$ eq.), [Fe( $\left.(\mathrm{acac})_{3}\right](0.50 \mathrm{~g}, 1.46 \mathrm{mmol}, 1.00 \mathrm{eq})$ and dvtms $(0.79 \mathrm{~g}, 4.25 \mathrm{mmol}, 2.90$ eq. $)$ were suspended in diethyleth- er $(40 \mathrm{~mL})$. Diethylaluminum ethoxide $(1.50 \mathrm{~mL}, 10.0 \mathrm{mmol}, 6.85$ eq) was added dropwise. After it was stirred for $30 \mathrm{~min}$, the solution became dark green. The reaction mixture was further stirred for $5 \mathrm{~h}$. Diethylether was evaporated under reduced pressure leaving a green oil which was triturated with pentane to form a green solid that was washed 3 times with pentane $(3 \times 5 \mathrm{~mL})$. The solid was dried under reduced pressure affording $0.77 \mathrm{~g}(81 \%)$ of a green solid. X-ray quality crystals were obtained by cooling a saturated toluene solution of the title complex to $-20^{\circ} \mathrm{C}$. Anal. found (calcd.) for $\mathrm{C}_{34} \mathrm{H}_{42} \mathrm{FeOP}_{2} \mathrm{Si}_{2}$ : C, 58.12 (63.74); $\mathrm{H}, 6.17$ (6.61). Inconsistencies observed in the elemental analysis might be due to partial sample decomposition during work up.

[Fe(dppp)(dvtms)] (2). 1,2-Bis(diphenylphosphino)propane (1.30 g, $3.15 \mathrm{mmol}, 1.07$ eq.), [Fe(acac) 3 ] (1.04 g, $2.94 \mathrm{mmol}, 1.00 \mathrm{eq})$ and dvtms (1.17 g, $6.28 \mathrm{mmol}, 2.14$ eq.) were suspended in diethylether $(30 \mathrm{~mL})$. Diethylaluminum ethoxide $(3.10 \mathrm{~mL}, 20.7 \mathrm{mmol}, 7.04$ eq) was added dropwise. The reaction mixture was stirred overnight. Diethylether was evaporated under reduced pressure leaving a dark green oil which was dissolved in pentane $(10 \mathrm{~mL})$ and the solution was cooled to $-80^{\circ} \mathrm{C}$ for $2 \mathrm{~h}$. The solid formed was isolated by decantation and dried under reduced pressure at $-80{ }^{\circ} \mathrm{C}$ affording $1.15 \mathrm{~g}$ of a green powder. A second crop was obtained after cooling the pentane filtrate to $-20{ }^{\circ} \mathrm{C}$ overnight. Combined crops yielded $1.37 \mathrm{~g}(71 \%)$ of product. X-ray quality crystals were obtained by cooling down to room temperature a filtered saturated diethylether solution of the title product. Selected IR data $\left(\mathrm{cm}^{-1}\right)$ : 3057(w), 3016(w), 2950(w), 2905(w), 2859(w), 1481(m), 1431(s), 1290(s), 1242(s), 1180(m), 964(s), 820(s), 771(s), 739(vs), 693(vs), 499(vs). Elemental analyses (C, H) of this compound were attempted 4 times on 4 different crystalline samples. The closest agreement between experimental and theoretical values was: Anal. found (calcd.) for $\mathrm{C}_{35} \mathrm{H}_{44} \mathrm{FeOP}_{2} \mathrm{Si}_{2}$ : C, 62.31 (64.21); H, 6.86 (6.77).

[Fe( $\left.\mathrm{PMe}_{3}\right)_{2}$ (dvtms)] (3). $\mathrm{PMe}_{3}(4.40 \mathrm{~mL}, 4.40 \mathrm{mmol}, 3.10$ eq.), [Fe(acac) $\left.)_{3}\right](0.50 \mathrm{~g}, 1.42 \mathrm{mmol}, 1.00$ eq.) and dvtms (0.29 g, 1.56 mmol, 1.10 eq.) were suspended in diethylether $(20 \mathrm{~mL})$. Diethylaluminum ethoxide $(1.50 \mathrm{~mL}, 9.94 \mathrm{mmol}, 7.00$ eq.) was added dropwise and the reaction mixture was stirred for $1 \mathrm{~h}$. Diethylether was evaporated under reduced pressure leaving a blue oil which was dissolved in the minimum of pentane (approx. $3 \mathrm{~mL}$ ). The blue solution was filtered with a filter cannula and the extract was cooled to $-80^{\circ} \mathrm{C}$ for $24 \mathrm{~h}$. A small amount of blue solid formed that was filtered off from the blue solution. The blue extract was cooled to $-80^{\circ} \mathrm{C}$ for 2 days giving blue crystals which were isolated and dried under vacuum $(0.11 \mathrm{~g}, 19 \%$ yield $)$. X-ray quality crystals were obtained by storing a pentane solution of the title product at $34{ }^{\circ} \mathrm{C}$ for 3 days. Reliable elemental analysis could not be performed owing to the oily nature of the product at ambient temperature. ${ }^{1} \mathrm{H}$ NMR (300 MHz, $\left.\mathrm{C}_{6} \mathrm{D}_{6}, 300 \mathrm{~K}\right) \delta(\mathrm{ppm})-7.44$ (br. s), 0.0355 (br. s), 1.74 (m), 9.25 (s), 33.3 (s).

[Fe(pyNMeP( $\left.\left(\mathrm{Pr}_{2}\right)(\mathrm{dvtms})\right]$ (4). N-(diisopropylphosphino)-Nmethylpyridin-2-amine $(0.97 \mathrm{~g}, 1.95 \mathrm{mmol}, 1.05 \text { eq.), [Fe(acac) })_{3}$ ] $(0.66 \mathrm{~g}, 1.86 \mathrm{mmol}, 1.00 \mathrm{eq})$ and dvtms $(1.09 \mathrm{~g}, 5.84 \mathrm{mmol}, 3.14$ eq.) were suspended in diethylether $(30 \mathrm{~mL})$. Diethylaluminum ethoxide $(2.00 \mathrm{~mL}, 13.0 \mathrm{mmol}, 7.00 \mathrm{eq})$ was added dropwise and the reaction mixture was stirred overnight. The solution was filtered with a filter cannula and the solvent was evaporated under reduced pressure. Pentane was added and the solid formed was washed twice with pentane then dissolved in the minimum of diethylether and the solution was filtered and placed at $-20{ }^{\circ} \mathrm{C}$ overnight giving a first crop of brown crystals $(0.39 \mathrm{~g})$. A second crop was obtained after cooling the diethylether filtrate to $-20^{\circ} \mathrm{C}$ overnight. By combining the two crops a total of $0.44 \mathrm{~g}(48 \%)$ of product was isolated. X-ray quality crystals were obtained by cooling a pentane/toluene solution of the title complex to $-34^{\circ} \mathrm{C}$. Anal. 
found (calcd.) for $\mathrm{C}_{20} \mathrm{H}_{39} \mathrm{FeN}_{2} \mathrm{OPSi}_{2}$ : C, 51.36 (51.49); $\mathrm{H}, 8.55$ (8.43); N, 5.95 (6.00). Selected IR data $\left(\mathrm{cm}^{-1}\right): 3037(\mathrm{~m}), 2952(\mathrm{~m})$, 2923(m), 2876(m), 1598(s), 1565(m), 1473(s), 1330(m), $1299(\mathrm{~s})$, 1242(s), 1188(s), 967(vs), 858(vs), 825(vs), 776(vs), 569(s), 472(vs).

[Fe(dipe)(dvtms)] (5). 1,2-Bis(diisopropylphosphino)ethane $(0.82 \mathrm{~g}$, $2.97 \mathrm{mmol}, 1.05$ eq.), [Fe(acac) 3 ] (1.00 g, $2.82 \mathrm{mmol}, 1.00$ eq.) and dvtms (1.58 g, $8.49 \mathrm{mmol}, 3.01 \mathrm{eq}$.$) were suspended in diethylether$ $(30 \mathrm{~mL})$. Diethylaluminum ethoxide $(3.00 \mathrm{~mL}, 20.0 \mathrm{mmol}, 7.09$ eq.) was added dropwise and the reaction mixture was stirred overnight. Diethylether was evaporated under reduced pressure leaving a blue oil which was triturated with pentane to form a blue solid that was washed twice $(2 \times 5 \mathrm{~mL})$ with pentane and dried under vacuum affording $0.80 \mathrm{~g}$ of product. The combined blue extracts were cooled to $-20{ }^{\circ} \mathrm{C}$ and the solid formed was isolated and dissolved in the minimum amount of ether. The solution was cooled to $-20{ }^{\circ} \mathrm{C}$ giving $0.35 \mathrm{~g}$ of blue crystals. A total of $1.15 \mathrm{~g}(81 \%)$ of product was isolated. Anal. found (calcd.) for $\mathrm{C}_{22} \mathrm{H}_{50} \mathrm{FeOP}_{2} \mathrm{Si}_{2}$ : C, 52.14 (52.37); H, 9.93 (9.99). Selected IR data $\left(\mathrm{cm}^{-1}\right): 2953(\mathrm{~s})$, 2894(m), 2870(m), 1601(w), 1532(w), 1458(m), 1287(s), 1238(s), 1186(s), 964(s), 859(s), 824(vs), 769(vs), 718(s), 707(s), 686(s), 667(s), 642(s), 621(s), 600(s), 578(s).

[Fe(dppm $\left.)_{2}\left(\mathrm{C}_{2} \mathrm{H}_{4}\right)\right]$ (6). 1,2-Bis(diphenylphosphino)methane (4.00 $\mathrm{g}, 10.4 \mathrm{mmol}, 2.04 \mathrm{eq})$ and $\left[\mathrm{Fe}(\mathrm{acac})_{3}\right](1.77 \mathrm{~g}, 5.01 \mathrm{mmol}, 1.00 \mathrm{eq})$ were suspended in toluene $(50 \mathrm{~mL})$. The suspension was chilled to $0{ }^{\circ} \mathrm{C}$ and diethylaluminum ethoxide $(5.10 \mathrm{~mL}, 34.0 \mathrm{mmol}, 6.78$ eq.) was added dropwise and the reaction mixture was stirred for 1 $\mathrm{h}$ at $0{ }^{\circ} \mathrm{C}$ and $2 \mathrm{~h}$ at ambient temperature. The solid formed was collected by filtration and washed several times with diethylether ( 3 times $10 \mathrm{~mL}$ ) and pentane ( 2 times $10 \mathrm{~mL}$ ). The solid was dried under vacuum affording $3.56 \mathrm{~g}(83 \%)$ of an orange powder. Selected IR data $\left(\mathrm{cm}^{-1}\right): 3053(\mathrm{w}), 2997(\mathrm{w}), 2952(\mathrm{w}), 2932(\mathrm{w}), 2896(\mathrm{w})$, 1584(w), 1571(w), 1479(m), 1432(s), 1146(s), 1077(m), 1053(m), 1025(m), 767(s), 732(vs), 688(vs), 502(vs), 483(vs). ${ }^{1} \mathrm{H}$ NMR (300 $\left.\mathrm{MHz}, \mathrm{C}_{6} \mathrm{D}_{6}, 300 \mathrm{~K}\right) \delta(\mathrm{ppm}) 2.22$ (br. s, $\left.\mathrm{CH}_{2 \mathrm{dppm}}, 4 \mathrm{H}\right), 3.86\left(\mathrm{~m}, \mathrm{CH}_{2}\right.$ ethylene, $2 \mathrm{H}), 4.35\left(\mathrm{~m}, \mathrm{CH}_{2}\right.$ ethylene, $\left.2 \mathrm{H}\right), 6.87-7.38\left(\mathrm{H}_{\text {aromatics, }}, 2 \mathrm{H}\right)$. ${ }^{31} \mathrm{P}\left\{{ }^{1} \mathrm{H}\right\}$ NMR (121 MHz, $\left.\mathrm{C}_{6} \mathrm{D}_{6}, 300 \mathrm{~K}\right) \delta$ (ppm) 23.9 (br.s). Anal. found (calcd.) for $\mathrm{C}_{54} \mathrm{H}_{48} \mathrm{FeP}_{4}$ : C, 73.32 (73.25); $\mathrm{H}, 5.69$ (5.67).

[Fe(dppa) $\left.{ }_{2}\left(\mathrm{C}_{2} \mathrm{H}_{4}\right)\right]$ (7). 1,2-Bis(diphenylphosphino)amine $(0.45 \mathrm{~g}$, $1.17 \mathrm{mmol}, 2.06 \mathrm{eq})$ and $\left[\mathrm{Fe}(\mathrm{acac})_{3}\right](0.20 \mathrm{~g}, 0.57 \mathrm{mmol}, 1.00 \mathrm{eq})$ were suspended in diethylether $(10 \mathrm{~mL})$. Diethylaluminum ethoxide $(0.60 \mathrm{~mL}, 3.90 \mathrm{mmol}, 6.85 \mathrm{eq})$ was added dropwise and the reaction mixture was stirred overnight. The volatiles were evaporated under reduced pressure and the orange solid was washed three times with pentane and dried under vacuum, affording $0.44 \mathrm{~g}$ (87\%) of a light brown powder. X-ray quality crystals of 7 were obtained by cooling a saturated toluene solution of the title complex to $-20{ }^{\circ} \mathrm{C}$. Anal. found (calcd.) for $\mathrm{C}_{50} \mathrm{H}_{46} \mathrm{FeN}_{2} \mathrm{P}_{4}$ : C, 37.59 (70.27); H, 2.94 (5.43); N, 2.06 (3.28). These considerable deviations regarding carbon and hydrogen microanalyses might be due to decomposition of the complex during work up resulting in the presence of inorganic materials in the sample. Selected IR data $\left(\mathrm{cm}^{-}\right.$ $\left.{ }^{1}\right)$ : 3054(w), 1591(w), 1526(w), 1483(w), 1436(s), 1383(w), 1123(s), 1096(m), 1064(m), 1027(m), 998(w), 827(m), 747(m), 724(s), 691(vs), 554(vs), 508(vs).

[Fe(dppe $\left.)_{2}\left(\mathrm{C}_{2} \mathrm{H}_{4}\right)\right]$ (8). 1,2-Bis(diphenylphosphino)ethane $(6.87 \mathrm{~g}$, $17.2 \mathrm{mmol}, 2.03 \mathrm{eq})$ and $\left[\mathrm{Fe}(\mathrm{acac})_{3}\right](3.00 \mathrm{~g}, 8.49 \mathrm{mmol}, 1.00 \mathrm{eq})$ were suspended in diethylether $(100 \mathrm{~mL})$. Diethylaluminum ethoxide $(8.90 \mathrm{~mL}, 59.4 \mathrm{mmol}, 7.00$ eq.) was added dropwise. The initially red solution turned yellow, then brown until a red solid precipitated. After the suspension was stirred for $2 \mathrm{~h}$, the solid formed was collected by filtration with a filter cannula and washed several times with diethylether $(5 \times 10 \mathrm{~mL})$. The solid was dried under reduced pressure, affording $6.37 \mathrm{~g}(85 \%)$ of a deep red powder. X-ray quality crystals were obtained by vapor diffusion of pentane into a concentrated toluene solution of the title complex. Selected IR data $\left(\mathrm{cm}^{-1}\right)$ : 3048(w), 3016(w), 2906(w), $1601(\mathrm{w})$, 1531(m), 1478(m), 1431(s), 1160(m), 1151(m), 1094(m), 1065(m), 1051(m), 1027(m), 872(m), 818(m), 793(m), 738(s), 692(vs), 655(s), 515(vs), 502(vs). ${ }^{1} \mathrm{H}$ NMR (300 MHz, $\left.\mathrm{C}_{6} \mathrm{D}_{6}, 300 \mathrm{~K}\right) \delta(\mathrm{ppm}) 0.93$ $\left(\mathrm{m}, \mathrm{CH}_{2 \text { ethylene, }}, \mathrm{H}\right), 1.13\left(\mathrm{~m}, \mathrm{CH}_{2 \text { ethylene, }}, 2 \mathrm{H}\right), 1.13\left(\mathrm{~m}, \mathrm{CH}_{2 \text { dppe }}, 2 \mathrm{H}\right)$, 2.10 (m, $\left.\mathrm{CH}_{2 \text { dppe }}, 4 \mathrm{H}\right), 2.44\left(\mathrm{~m}, \mathrm{CH}_{2 \text { dppe, }}, 2 \mathrm{H}\right), 6.35-7.87\left(\mathrm{H}_{\text {aromatics }}\right.$, $20 \mathrm{H}) .{ }^{31} \mathrm{P}\left\{{ }^{1} \mathrm{H}\right\} \mathrm{NMR}\left(121 \mathrm{MHz}, \mathrm{C}_{6} \mathrm{D}_{6}, 300 \mathrm{~K}\right) \delta(\mathrm{ppm}) 78.9\left(2 \mathrm{P}, \mathrm{t}, \mathrm{J}_{P P}\right.$ $=39.19$ and $39.58 \mathrm{~Hz}), 95.5\left(2 \mathrm{P}, \mathrm{t}, \mathrm{J}_{P P}=39.13\right.$ and $\left.39.64 \mathrm{~Hz}\right) \cdot{ }^{13} \mathrm{C}$ NMR $\left(75 \mathrm{MHz}, \mathrm{C}_{6} \mathrm{D}_{6}, 300 \mathrm{~K}\right) \delta(\mathrm{ppm}) 25.97$ (s, $\mathrm{CH}_{2}$ ethylene, 2C), 29.27 ( $\mathrm{m}, \mathrm{CH}_{2 \text { dppe, }}$ 2C), 35.45 ( $\left.\mathrm{m}, \mathrm{CH}_{2 \text { dppe }}, 2 \mathrm{C}\right), 126.86,128.38$, 131.8, 133.5, 142.8, 143.9, 145.6. Anal. found (calcd.) for $\mathrm{C}_{54} \mathrm{H}_{52} \mathrm{FeP}_{4}$ : C, 73.68 (73.64); H, 6.05 (5.95).

[Fe(dppe)(PMe $)_{3}$ (3-hexyne)] (9). Complex 2 (0.21 g, $0.32 \mathrm{mmol}$, 1.00 eq.) was dissolved in diethylether $(10 \mathrm{~mL})$ and $\mathrm{PMe}_{3}(0.96 \mathrm{~mL}$, $0.960 \mathrm{mmol}, 2.99$ eq.) was added. The solution was cooled to -40 ${ }^{\circ} \mathrm{C}$ and 3-hexyne (0.26 g, $3.21 \mathrm{mmol}, 10.0$ eq.) was added. The reaction mixture was allowed to warm to room temperature and was stirred overnight. Then the diethylether was evaporated, the residue was extracted with pentane $(5 \times 3 \mathrm{~mL})$ and filtered; the green filtrate was concentrated to approx. one third of its original volume and stored at $-20{ }^{\circ} \mathrm{C}$ overnight. A solid formed that was isolated and dried under vacuum affording $0.05 \mathrm{~g}(28 \%)$ of a green crystalline material. ${ }^{1} \mathrm{H}$ NMR (300 MHz, $\left.\mathrm{C}_{6} \mathrm{D}_{6}, 300 \mathrm{~K}\right) \delta(\mathrm{ppm}) 0.557$ (br. s, $\mathrm{CH}_{3 \text { PMe3 }}, 9 \mathrm{H}$ ), 1.49 (br. s, $\mathrm{CH}_{3 \text { 3-hexyne, }}, 6 \mathrm{H}$ ), 2.10 (br. s, $\mathrm{CH}_{23 \text {-hexyne, }}$ $4 \mathrm{H}), 3.24$ (br. s, $\left.\mathrm{CH}_{2 \text { dppe }}, 4 \mathrm{H}\right), 7.03$ (s, $\left.\mathrm{CH}_{\text {PPh2 meta }+ \text { para }}, 12 \mathrm{H}\right), 7.50$ (d, $\left.\mathrm{CH}_{\text {Pph2 ortho }}, 8 \mathrm{H}\right) .{ }^{31} \mathrm{P}\left\{{ }^{1} \mathrm{H}\right\} \mathrm{NMR}\left(121 \mathrm{MHz}, \mathrm{C}_{6} \mathrm{D}_{6}, 300 \mathrm{~K}\right) \delta(\mathrm{ppm})$ $30.09\left(1 \mathrm{P}, \mathrm{t}, \mathrm{J}_{P P}=24.08 \mathrm{~Hz}\right), 106.3\left(2 \mathrm{P}, \mathrm{t}, \mathrm{J}_{P P}=24.10 \mathrm{~Hz}\right) .{ }^{13} \mathrm{C} \mathrm{NMR}$ $\left(75 \mathrm{MHz}, \mathrm{C}_{6} \mathrm{D}_{6}, 300 \mathrm{~K}\right) \delta(\mathrm{ppm}) 14.66,22.85,27.99,31.70,32.14$, $131.17,132.81,141.23,144.48,189.44$. Elemental analyses $(\mathrm{C}, \mathrm{H})$ of this compound were attempted 3 times on 3 crystalline samples. The closest agreement between experimental and theoretical values was: Anal. found (calcd.) for $\mathrm{C}_{35} \mathrm{H}_{43} \mathrm{FeP}_{3}$ : C, 54.16 (68.63); $\mathrm{H}, 3.76$ (7.08). These considerable deviations regarding carbon and hydrogen microanalyses might be explained by the presence of inorganic material. Selected IR data $\left(\mathrm{cm}^{-1}\right)$ : 3044(w), 2954(w), 2898(m), 1431(s), 1267(s), 1092(s), 933(s), 741(s), 694(vs), 656(vs), 630(s), 517(vs), 497(vs), 482(vs).

Procedure for the cyclotrimerization of 3-hexyne The complex catalyst (typically $0.2 \mathrm{mmol}$ ) was charged in a Schlenk flask in the glovebox and dissolved in THF $(5 \mathrm{~mL}$ ). The substrate (typically 2.0 mmol of 3-hexyne) was then added to the solution. The reaction mixture was stirred at ambient temperature for $48 \mathrm{~h}$ under argon atmosphere. After $48 \mathrm{~h}$ the reaction was quenched with approx. 5 $\mathrm{mL}$ aqueous $\mathrm{H}_{2} \mathrm{SO}_{4}(10 \mathrm{wt} \%)$. The solution was transferred into a separating funnel and the organic phase was collected. The aqueous phase was extracted twice with diethylether. The combined organic phases were analyzed by GC-MS.

Solid state NMR. The natural abundance solid-state ${ }^{13} \mathrm{C}$ NMR spectrum of complex 5 was acquired on a Bruker Avance III spectrometer operating at an external magnetic field strength of $11.7 \mathrm{~T}$ (corresponding to a ${ }^{13} \mathrm{C}$ Larmor frequency of $125.7 \mathrm{MHz}$ ) using a Bruker HX $2.5 \mathrm{~mm}$ wide-bore MAS probe. The powdered sample was packed in a standard $2.5 \mathrm{~mm} \mathrm{ZnO}_{2}$ rotor in an Argon-filled glovebox, then placed in a sealed glass tube before removal from the glovebox in order to protect the sample from oxygen. Immediately before measurement, the sealed tube was opened and the rotor was quickly inserted into the MAS probe, and simultaneously spun to a rate of $31.25 \mathrm{kHz}$ (corresponding to a $32 \mu$ s rotor period) while cooling the stator to a sample temperature of approximately $300 \mathrm{~K}$ using a Bruker BCU XTreme cooling unit. Nitrogen gas dried to a dew point of $-80^{\circ} \mathrm{C}$ was used for sample rotation. 
The $\pi / 2$ excitation pulse length was $2.1 \mu$ s (corresponding to an RF field strength of $119 \mathrm{kHz}$ ) at an offset of $270 \mathrm{ppm}$. Due to the broad span of ${ }^{13} \mathrm{C}$ resonances we employed short, high-powered adiabatic Tanh/Tan pulses (SHAPs) ${ }^{24}$ to refocus the chemical shift evolution. ${ }^{25}$ The pulses were $32 \mu$ s in length, and swept through 5 $\mathrm{MHz}$ with an RF field strength of $119 \mathrm{kHz}$. No ${ }^{1} \mathrm{H}$ decoupling was used during acquisition. Using a recovery time of $30 \mathrm{~ms}, 2 \mathrm{M}$ scans were acquired resulting in a total experiment time of 19.2 hours.

DFT calculations. Complex 5 and the NMR reference compound tetramethylsilane (TMS) were fully optimized with DFT, employing the hybrid PBEO functional, ${ }^{26}$ Grimme's D3 dispersion correction with Becke-Johnson damping, ${ }^{27}$ and a locally dense Gaussian basis set using def2-TZVP for Fe and def2-SVP for main group elements $^{28}$ as implemented in the Turbomole code. ${ }^{29}$ All calculations for the $\mathrm{Fe}^{0}$ complex $\mathbf{5}$ were done in vacuo for a triplet ground state. The initial model for the structure of $\mathbf{5}$ was built from the coordinates of the framework atoms of the closely related complex 1 obtained crystallographically, and substituting the $\mathrm{Ph}$ groups of the dppe ligand of 1 with ${ }^{i} \operatorname{Pr}$ moieties. A frequency calculation confirmed that the optimized structure is a true minimum, finding that all eigenvalues of the mass-weighted Hessian are positive.

The total PNMR shielding tensor is a sum of hyperfine and orbital shielding terms. The hyperfine shielding calculations were performed with two approaches, allowing to assess the importance of spin-orbit coupling. The results according to the recent formulation of Kurland-McGarvey PNMR theory ${ }^{30}$ in terms of EPR property tensors by Vaara et al. ${ }^{17}$ were compared to the "doublet-like" approximation neglecting all SOC effects (see Supporting Information). The temperature $300 \mathrm{~K}$ was used in all PNMR calculations.

The EPR g-tensor, zero-field-splitting (ZFS, D-) tensor, and hyperfine coupling tensors were calculated in Orca ${ }^{31}$ using the PBE0 functional. For both $g$ - and D-tensors the spin-orbit meanfield approximation ${ }^{32}$ was applied to the spin-orbit matrix elements in the Breit-Pauli form. The basis used in the DFT structure optimizations was enhanced with diffuse functions optimized for molecular property calculations, ${ }^{33}$ thus employing def2-TZVPD and def2-SVPD bases for $\mathrm{Fe}$ and main group elements, respectively. Van Wüllen's pre-factors for ZFS contributions from different spin channels were utilized. ${ }^{34}$ Fermi-contact and spin-dipolar terms of HFC were calculated using def2-TZVPD and IGLO-III ${ }^{35}$ basis sets for $\mathrm{Fe}$ and main group elements, respectively.

The ${ }^{13} \mathrm{C}$ orbital shielding tensors of TMS and complex 5 were calculated with gauge-including atomic orbitals ${ }^{36}$ using Gaussian package. ${ }^{37}$ The PBEO functional and the above defined HFC basis were employed. The calculated ${ }^{13} \mathrm{C}$ isotropic reference shielding, $\sigma_{K}^{\text {ref }}$, was $185.7 \mathrm{ppm}$ and the resulting ${ }^{13} \mathrm{C}$ isotropic shift $\delta_{K}$ was obtained from the total isotropic PNMR shielding $\sigma_{K}$ as

$$
\delta_{K}=\sigma^{\text {ref }}-\sigma_{K}
$$

\section{ASSOCIATED CONTENT}

\section{Supporting Information}

Text, figures, tables, CIF files giving detailed experimental, analytical and spectral data for all new compounds, crystallographic data for 1-4 and 6, 8 and 9 and solid state NMR and computational details for the determination of the structure of 5 . The Supporting Information is available free of charge on the ACS Publications website. CIF files have also been deposited with the CCDC and can be obtained on request free of charge, by quoting the deposi- tion numbers 1489026-1489029, 1497593-1497594 and 1510841.

\section{AUTHOR INFORMATION}

\section{Corresponding Author}

*E-mail for P.-A. B: pierre-alain.breuil@ifpen.fr

The authors declare no competing financial interest.

\section{ACKNOWLEDGMENTS}

We gratefully acknowledge IFP Energies nouvelles, the TGIRRMN-THC Fr3050 CNRS, the European Research Council under the European Union's Horizon 2020 Research and Innovation Programme (Grant 648974 "P-MEM-NMR") and the European Union's Seventh Framework Programme (FP7-PEOPLE-2012-ITN 317127 "pNMR") for the support.

\section{REFERENCES}

(1) a) Bauer, I.; Knölker, H.-J. Chem. Rev. 2015, 115, 3170-3387. b) Burcher, B.; Breuil, P.-A. R.; Magna, L.; Olivier-Bourbigou, H. in Iron Catalysis II vol. 50, (Ed : E. Bauer), Springer International Publishing Switzerland, 2015, pp. 217-258.

(2) a) Lavallo, V.; El-Batta, A.; Bertrand, G.; Grubbs, R. H. Angew. Chem., Int. Ed. 2011, 50, 268-271. b) Ung, G.; Rittle, J.; Soleilhavoup, M.; Bertrand, G.; Peters, J. C. Angew. Chem. Int. Ed. 2014, 53, 8427-8431. c) Danopoulos, A. A.; Wright, J. A.; Motherwell, W. B. Chem. Comm. 2005, 784-786. d) Brennessel, W. W.; Jilek, R. E.; Ellis, J. E. Angew. Chem. Int. Ed. 2007, 46, 6132 6136. e) Werncke, C. G.; Bunting, P. C.; Duhayon, C.; Long, J. R.; Bontemps, S.; Sabo-Etienne, S. Angew. Chem. Int. Ed. 2015, 54, 245-248. f) Zadrozny, J. M.; Xiao, D. J.; Atanasov, M.; Long, G. J.; Granjean, F.; Neese, F.; Long, J. R. Nature Chem. 2013, 5, 577-581. g) Danopoulous, A. A.; Braunstein, P., Monakhov, K. Yu; van Leusen, J.; Kögerler, P; Clémancey, M.; Latour, J.-M.; Benayad, A; Tromp, M; Rezabalh, E.; Frison, G. Dalton Trans., 2017.

(3) a) Hoyt, J. M.; Schmidt, V. A.; Tondreau, A. M.; Chirik, P. J. Science 2015, 349, 960-963. b) Anderson, J. S.; Rittle, J.; Peters, J. C. Nature 2013, 501, 84-88. c) Creutz, S. E.; Peters, J. C. J. Am. Chem. Soc. 2014, 136, 1105-1115. d) Ung, G.; Peters, J. C. Angew. Chem. Int. Ed. 2015, 54, 532-535. e) Boddien, A.; Loges, B.; Gärtner, F.; Toborg, C.; Fumino, K.; Junge, H.; Ludwig, R.; Beller, M. J. Am. Chem. Soc. 2010, 132, 8924-8934. f) Fürstner, A.; Majima, K.; Martín, R.; Krause, H.; Kattnig, E.; Goddard, R.; Lehmann, C. W. J. Am. Chem. Soc. 2008, 130, 1992-2004. g) Fürstner, A.; Martín, R.; Krause, H.; Seidel, G.; Goddard, R.; Lehmann, C. W. J. Am. Chem. Soc. 2008, 130, 8773-8787. h) Bart, S. C.; Lobkovsky, E.; Chirik, P. J. J. Am. Chem. Soc. 2004, 126, 13794-13807. i) Wang, C.; Li, X.; Wu, F.; Wan, B. Angew. Chem. Int. Ed. 2011, 50, 7162-7166.

(4) McNeill, E.; Ritter, T. Acc. Chem. Res. 2015, 48, 2330-2343.

(5) Selected examples of low-oxidation state iron complexes stabilized by nitrogen-based ligands: a) Stoian, S. A.; Yu, Y.; Smith, J. M.; Holland, P. L.; Bominaar, E. L.; Münck, E. Inorg. Chem. 2005, 44, 4915-4922. b) Yu, Y.; Smith, J. M.; Flaschenriem, C. J.; Holland, P. L. Inorg. Chem. 2006, 45, 5742-5751. c) Smith, J. M.; Sadique, A. R.; Cundari, T. R.; Rogers, K. R.; Lukat-Rodgers, G.; Lachicotte, R. J.; Flaschenriem, C. J.; Vela, J.; Holland, P. L. J. Am. Chem. Soc. 2006, 128, 756-769. d) Chiang, K. P. Scarborough, C. C.; Horitani, M.; Lees, N. S.; Ding, K.; Dugan, T. R.; Brenessel, W. W.; Bill, E; Hoffman, B. M.; Holland, P. L. Angew. Chem. Int. Ed. 2012, 51, 3658-3662. e) Rodriguez, M. M.; Stubbert, B. D.; Scarborough, C. C.; Brennessel, W. W.; Bill, E.; Holland, P. L. Angew. Chem. Int. Ed. 2012, 51, 8247-8250. f) Coric, I.; Mercado, B. Q.; Bill, E.; Vinyard, D. J.; Holland, P. L. Na- 
ture 2015, 526, 96-99. g) Russell, S. K.; Lobkovsky, E.; Chirik, P. J. J. Am. Chem. Soc. 2011, 133, 8858-8851. h) Hoyt, J. M.; Sylvester, K. T.; Semproni, S. P.; Chirik, P. J. J. Am. Chem. Soc. 2013, 135, 4862-4877.

(6) For reviews treating of non-innocent ligands see: a) Blanchard, S.; Derat, E.; Desage-El Murr, M.; Fensterbank, L.; Malacria, M.; Mouriès-Mansuy, V. Eur. J. Inorg. Chem. 2012, 3, 376-389. b) Luca, O. R.; Crabtree, R. H. Chem. Soc. Rev. 2013, 42, 1440-1459. c) Khusnutdinova, J. R.; Milstein, D. Angew. Chem. Int. Ed. 2015, 54, 2-40.

(7) Selected references of P-based iron(0) complexes: a) Rathke, J. W.; Muetterties, E. L. J. Am. Chem. Soc. 1975, 97, 3272-3273. b) Tolman, C. A.; Ittel, S. D.; English, A. D.; Jesson J. P. J. Am. Chem. Soc. 1978, 100, 4080-4089. c) Ittel, S. D.; Van-Catledge, F. A.; Jesson, J. P. J. Am. Chem. Soc. 1979, 101, 3874-3884. d) Lindner, E.; Schauss, E.; Hiller, W.; Fawzi, R. Angew. Chem. Int. Ed. 1984, 23, 711-712. e) Boncella, J. M.; Green, M. L. H.; O'Hare, D. J. Chem. Soc., Chem. Commun. 1986, 8, 618-619. f) Baker, M. V.; Field, L. D. J. Am. Chem. Soc. 1986, 108, 7433-7434. g) Zenneck, U.; Frank, W. Angew. Chem. Int. Ed. 1986, 25, 831-833. h) Hoberg, H.; Jenni, K.; Raabe, E.; Krüger, C.; Schroth, G. J. Organomet. Chem. 1987, 320, 325-338. i) Brookhart, M.; Chandler, W. A.; Mister, A. C.; Santini, C. C.; White, P. S. Organometallics 1992, 11, 1263-1274. j) Elschenbroich, C.; Nowotny, M.; Behrendt, A.; Harms, K.; Wocadlo, S.; Pebler, J. J. Am. Chem. Soc. 1994, 116, 6217-6219. k) Hirano, M.; Akita, M.; Morikita, T.; Kubo, H.; Fukuoka, A.; Komiya, S. J. Chem. Soc., Dalton Trans. 1997, 19, 3453-3458. 1) Kubo, H.; Hirano, M.; Komiya, S. J. Organomet. Chem. 1998, 556, 89-95. m) Bennett, M. A.; Ditzel, E. J.; Hunter, A. D.; Khan, K.; Kopp, M. R.; Neumann, H.; Robertson, G. B.; Zech, H. J. Chem. Soc., Dalton Trans. 2000, 11, 1733-1741. n) Gilbert-Wilson, R.; Field, L. D.; Colbran, S. B.; Bhadbhade, M. M. Inorg. Chem. 2013, 53, 3043-3053.

(8) Bart, S. C.; Hawrelak, E. J.; Lobkovsky, E.; Chirik, P. J. Organometallics 2005, 24, 5518-5527.

(9) a) Hoberg, H.; Jenni, K. J. Organomet. Chem. 1986, 301, C59. C61. b) Bleeke, J. R.; Wittenbrink, R. J. J. Organomet. Chem. 1991, 405, 121-132. c) Geier, S.; Goddard, R.; Holle, S.; Jolly, P. W.; Krüger, C.; Lutz, F. Organometallics 1997, 16, 1612-1620. d) Hoberg, H.; Jenni, K.; Angermund, K.; Krüger, C. Angew. Chem. Int. Ed. Engl. 1987, 26, 153-155.

(10) Casitas, A.; Krause, H.; Goddard, R.; Fürstner, A. Angew. Chem. Int. Ed. 2015, 54, 1521-1526.

(11) Zhang, H.; Ouyang, Z.; Liu, Y.; Zhang, Q.; Wang, L.; Deng, L. Angew. Chem. Int. Ed. 2014, 53, 8432-8436.

(12) a) Marciniec, B.; Kownacki, I.; Taylor, R. Appl. Catal. A: General 2014, 486, 230-238. b) Kownacka, A.; Kownacki, I.; Kubicki, M.; Marciniec, B.; Taylor, R. J. Organomet. Chem. 2014, 750, 132-139. c) Marciniec, B.; Kownacka, A.; Kownacki, I.; Hoffmann; M.; Taylor, R. J. Organomet. Chem. 2015, 791, 58-65.

(13) a) Avent, A. G.; Lappert, M. F.; MacBeath, C. J. Organomet.Chem. 1995, 502, 163-167. b) Vollmüller, F.; Krause, J.; Klein, S.; Mägerlein, W.; Beller, M. Eur. J. Inorg. Chem. 2000, 8, 1825-1832. c) Harkal, S.; Jackstell, R.; Nierlich, F.; Ortmann, D.; Beller, M. Org. Lett. 2005, 7, 541-544.

(14) a) Weber, S. R.; Brintzinger, H. H. J. Organomet. Chem. 1977, 127, 45-54. b) Funhoff, A.; Schäufele, H.; Zenneck U. J. Organomet. Chem. 1988, 345, 331-339. c) Schmidt, U.; Zenneck, U. J. Organomet. Chem. 1992, 440, 187-190.

(15) a) Breschi, C.; Piparo, L.; Pertici, P.; Caporusso, A. M.; Vitulli, G. J. Organomet. Chem. 2000, 607, 57-63. b) Saino, N.; Kogure, D.; Kase, K.; Okamoto, S. J. Organomet. Chem. 2006, 691, 3129. 3136. c) Liu, Y.; Yan, X.; Yang, N.; Xi, C. Catal. Commun. 2011, 12, 489-492. d) Lipschutz, M. I.; Chantarojsiri, T.; Dong, Y.; Tilley, D. T. J. Am. Chem. Soc. 2015, 137, 6366-6372.

(16) Hata, G.; Kondo, H.; Miyake, A. J. Am. Chem. Soc. 1968, 90, 2278-2281
(17) Vaara, J.; Rouf, S. A.; Mareš, J. J. Chem. Theory Comput. 2015, 11, 4840-4849.

(18) a) Bühl, M.; Kabrede, H. J. Chem. Theory Comput. 2006, 2,12821290. b) Minenkov, Y.; Singstad, A.; Occhipintia, G.; Jensen, V. R. Dalton Trans., 2012, 41, 5526-5541.

(19) Kervern, G.; Pintacuda, G.; Zhang, Y.; Oldfield, E.; Roukoss, C.; Kuntz, E.; Herdtweck, E.; Basset, J.-M.; Cadars, S.; Lesage, A.; Copéret, C.; Emsley, L. J. Am. Chem. Soc. 2006, 128, 13545 13552.

(20) (a) Remenyi, C.; Reviakine, R.; Kaupp, M. J. Phys. Chem. A 2006, 110, 4021-4033. (b) Remenyi, C.; Reviakine, R.; Kaupp, M. J. Phys. Chem. B 2007, 111, 8290-8304.

(21) Fritscher, J.; Hrobárik, P.; Kaupp, M. Inorg. Chem. 2007, 46, 8146-8161.

(22) Half of the iron precursor being consumed.

(23) Ittel, S. D.; Tolman, C. A.; Krusic, J. P.; English, A. D.; Jesson, J. P. Inorg. Chem. 1978, 17, 3432-3438.

(24) (a) Kervern, G.; Pintacuda, G.; Emsley, L. Chem. Phys. Lett. 2007, 435, 157-162. (b) Hwang, T.-L.; P. C. M. van Zijl, P. C. M.; Garwood, M. J. Magn. Reson. 1998, 133, 200-203.

(25) Kervern, G.; D'Aléo, A.; Toupet, L.; Maury, O.; Emsley, L.; Pintacuda, G. Angew. Chem. Int. Ed. 2009, 48, 3082-3086.

(26) (a) Perdew, J. P.; Burke, K.; Ernzerhof, M. Phys. Rev. Lett. 1996, 77, 3865-3868. (b) Adamo, C.; Barone, V. J. Chem. Phys. 1999, $110,6158-6170$

(27) Grimme, S.; Antony, J.; Ehrlich, S.; Krieg, H. J. Chem. Phys. 2010, 132, 154104.

(28) Weigend, F.; Ahlrichs, R. Phys. Chem. Chem. Phys. 2005, 7, $3297-$ 3305.

(29) Ahlrichs, R.; Armbruster, M. K.; Bachorz, R. A.; Bär, M.; Baron, H.-P.; Bauernschmitt, R.; Bischoff, F. A.; Böcker, S.; Crawford, N.; Deglmann, P.; Della Sala, F.; Diedenhofen, M.; Ehrig, M.; Eichkorn, K.; Elliot, S.; Furche, F.; Glöß, A.; Haase, F.; Häser, M.; Hättig, C.; Hellweg, A.; Höfener, S.; Horn, H.; Huber, C.; Huniar, U.; Kattannek, M.; Klopper, W.; Köhn, A.; Kölmel, C.; Kollwitz, M.; May, K.; Nava, P.; Ochsenfeld, C.; Öhm, H.; Pabst, M.; Patzelt, H.; Rappoport, D.; Rubner, O.; Schäfer, A.; Schneider, U.; Sierka, M.; Tew, D. P.; Treutler, O.; Unterreiner, B.; von Arnim, M.; Weigend, F.; Weis, P.; Weiss, H.; Winter, N. Turbomole 6.3.1 ed., TURBOMOLE GmbH, 2011.

(30) Kurland, R. J.; McGarvey, B. R. J. Magn. Reson. 1970, 2, 286-301.

(31) Neese, F. WIREs Comput. Mol. Sci. 2012, 2, 73-78.

(32) (a) Heß, B. A.; Marian, C. M.; Wahlgren, U.; Gropen, O. Chem. Phys. Lett. 1996, 251, 365-371. (b) Neese, F. J. Chem. Phys. 2005, 122, 034107.

(33) Rappoport, D.; Furche, F. J. Chem. Phys. 2010, 133, 134105.

(34) Schmitt, S.; Jost, P.; van Wüllen, C. J. Chem. Phys. 2011, 134, 194113.

(35) Kutzelnigg, W.; Fleischer, U.; Schindler, M. in NMR - Basic Principles and Progress, Vol. 23, Springer, Heidelberg, 1990, pp. 165-262.

(36) Wolinski, K.; Hinton, J. F.; Pulay, P. J. Am. Chem. Soc. 1990, 112, 8251-8260.

(37) Frisch, M. J.; Trucks, G. W.; Schlegel, H. B.; Scuseria, G. E.; Robb, M. A.; Cheeseman, J. R.; Scalmani, G.; Barone, V.; Mennucci, B.; Petersson, G. A.; Nakatsuji, H.; Caricato, M.; Li, X.; Hratchian, H. P.; Izmaylov, A. F.; Bloino, J.; Zheng, G.; Sonnenberg, J. L.; Hada, M.; Ehara, M.; Toyota, K.; Fukuda, R.; Hasegawa, J.; Ishida, M.; Nakajima, T.; Honda, Y.; Kitao, O.; Nakai, H.; Vreven, T.; Montgomery Jr., J. A.; Peralta, J. E.; Ogliaro, F.; Bearpark, M. J.; Heyd, J.; Brothers, E. N.; Kudin, K. N.; Staroverov, V. N.; Kobayashi, R.; Normand, J.; Raghavachari, K.; Rendell, A. P.; Burant, J. C.; Iyengar, S. S.; Tomasi, J.; Cossi, M.; Rega, N.; Millam, N. J.; Klene, M.; Knox, J. E.; Cross, J. B.; Bakken, V.; Adamo, C.; Jaramillo, J.; Gomperts, R.; Stratmann, R. E.; Yazyev, O.; Austin, A. J.; Cammi, R.; Pomelli, C.; Ochterski, J. W.; Martin, R. L; Morokuma, K.; Zakrzewski, V. G.; Voth, G. A.; Salvador, P.; Dannenberg, J. J.; Dapprich, S.; 
Daniels, A. D.; Farkas, Ö.; Foresman, J. B.; Ortiz, J. V.; Cioslowski, J.; Fox, D. J. Gaussian, Inc., Wallingford, CT, USA, 2009.

Graphic for TOC

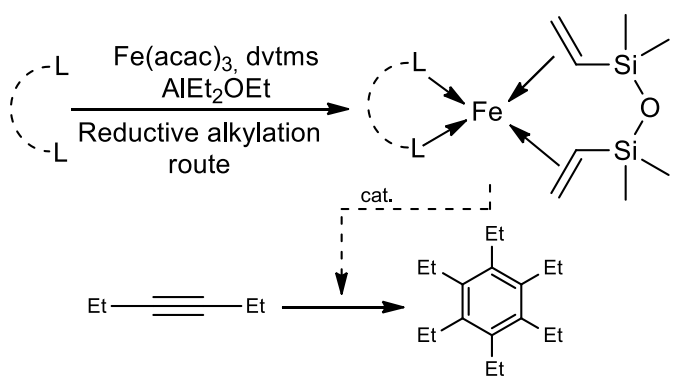

